\title{
Towards Sustainable Residential Buildings in Saudi Arabia According to the Conceptual Framework of "Mostadam" Rating System and Vision 2030
}

\author{
Ashraf Balabel ${ }^{1, *}$ and Mamdooh Alwetaishi ${ }^{2, *(D)}$ \\ 1 Department of Mechanical Engineering, College of Engineering, Taif University, P.O. Box 11099, \\ Taif 21944, Saudi Arabia \\ 2 Department of Civil Engineering, College of Engineering, Taif University, P.O. Box 11099, \\ Taif 21944, Saudi Arabia \\ * Correspondence: a.balabel@tu.edu.sa (A.B.); m.alwetaishi@tu.edu.sa (M.A.)
}

Citation: Balabel, A.; Alwetaishi, M. Towards Sustainable Residential Buildings in Saudi Arabia According to the Conceptual Framework of "Mostadam" Rating System and Vision 2030. Sustainability 2021, 13, 793. https://doi.org/10.3390/su13 020793

Received: 15 November 2020 Accepted: 7 January 2021 Published: 15 January 2021

Publisher's Note: MDPI stays neutral with regard to jurisdictional clai$\mathrm{ms}$ in published maps and institutional affiliations.

Copyright: $\odot 2021$ by the authors. Licensee MDPI, Basel, Switzerland. This article is an open access article distributed under the terms and conditions of the Creative Commons Attribution (CC BY) license (https:// creativecommons.org/licenses/by/ $4.0 /)$.

\begin{abstract}
Saudi Arabia vision 2030 adopts comprehensive development standards in all fields of Saudi society. To achieve such standards, many initiatives and programs have been launched to achieve sustainable goals while meeting the needs of the present without compromising the requirements of future generations. Sustainable buildings are highly important in achieving sustainable development goals due to their excellent ability to reduce energy consumption, increase building efficiency, and reduce harmful emissions of greenhouse gases. The Kingdom aims to be the largest investor in the world in the sustainable buildings sector. To this end, the "Mostadam" evaluation service was recently launched in order to assist existing and new buildings in achieving sustainable building standards in a way that is in keeping with the privacy and principles of Saudi society. The present paper presents an extensive investigation to assess the current state of sustainable buildings in Saudi cities. Moreover, the main categories of sustainable residential buildings according to the "Mostadam" rating systems are discussed, and the potential of such categories in Saudi Arabia is explored. Finally, suggestions are given for some practical strategies and future policies targeting the total transformation towards sustainable buildings and, consequently, towards sustainable cities. This will have a great impact on achieving comprehensive sustainable development in Saudi Arabia in line with vision 2030.
\end{abstract}

Keywords: Mostadam; rating systems; sustainable residential buildings; Saudi Arabia; vision 2030

\section{Introduction}

The Kingdom of Saudi Arabia is committed to implementing sustainable development goals, placing them as a top priority in line with its specific principles. The Kingdom's vision 2030 as a whole is consistent with the sustainable development goals. This ambitious vision and the related multifaceted implementation programs provide the basis for supporting the sustainable development goals in the national planning process.

Buildings are responsible for the majority of a city's overall pollution in the form of carbon emissions, and they represent almost 40 percent of its overall energy consumption. Therefore, the Kingdom has prepared many strategies, plans, and axes for the promotion of sustainable development goals, including the highly important axis of transformation towards sustainable buildings as a key element in the future development of sustainable cities and societies [1]. A reduction in building emissions requires a combination of technological advancements in low-carbon energy systems and initiatives to reduce building-related energy use in both new and existing buildings. This will result in the achievement of prosperity for both citizens and residents, making the Kingdom an attractive destination for travel and tourism.

The Kingdom of Saudi Arabia has witnessed rapid urban growth in recent years, especially in its major cities, due to remarkable economic and social growth, leading to 
an increase in its number of cities, which reached a total of 285 in 2014. This has resulted in many modern urban challenges. In light of this, the "Future Saudi Cities" program was launched and implemented in order to achieve the sustainable urbanization of the Kingdom in response to the urban challenges arising from this rapid growth and to support the Kingdom's urban strategy of achieving balanced development.

The "Future Saudi Cities" program is considered to be a promising program that is fully integrated with the Kingdom's vision of 2030 through its distinct goals and outputs. The main objective of this program is to develop environmentally sustainable cities with adequate infrastructure and high quality of life. This program also aims to achieve sustainable urbanization in the Kingdom in accordance with international standards for sustainability. This can be achieved through the evaluation of the current situation of Saudi cities, performing challenge analyses, and, finally, the development of pioneering strategic plans and projects. In the context of sustainable cities, there is an underlying consideration of environmental impact. These factors include, but are not limited to, water, air pollution, energy, and waste. Saudi sustainable cities should aim to optimize economic, financial, social, and environmental sustainability goals in order to enable these cities to function better and more healthily.

Sustainable buildings (also termed "green buildings" or "high-performance buildings") are designed, built, and operated in a resource-efficient manner. The main objective of sustainable building strategies is to reduce the overall impact on human health and the environment and to reduce the overall energy consumption [2,3]. The concept of sustainable buildings is still the subject of significant interest and debate worldwide. In the last two decades, a great emphasis has been placed on sustainable buildings, especially in Saudi Arabia, due to their economic, social, and environmental impacts [4-10]. Consequently, investment in the sustainable buildings sector in Saudi Arabia is currently the third-highest investment of this kind in the world, and the Kingdom is set to become the world leader in this industry.

Globally, different sustainable building standards have recently been developed and applied, including the "Building Research Establishment's Environmental Assessment Method" (BREEAM) in the UK, the comprehensive assessment system for building environmental efficiency (CASBEE) in Japan, EcoProfile in Norway, and Leadership in Energy and Environmental Design (LEED) in the USA.

LEED is an internationally recognized green building certification system developed by the US Green Building Council (USGBC). This certification system provides a concise framework for green building categories and items and a global verification that a building was designed, built, and operated in accordance with these. LEED can be applied for all types of buildings - e.g., residential; commercial; and, more recently, healthcare facilities. LEED also includes both new and existing buildings. Unfortunately, some indicators of the LEED certification system are not suitable for use in other countries, such as Saudi Arabia. Accordingly, different sustainable building assessment schemes have been developed and applied that are specifically adapted to the local built environment of Saudi Arabia [4,5,11].

More recently, Saudi Arabia has developed a new green building rating system called "Mostadam" to improve water and energy sustainability with assistance from the country's Ministry of Housing and the sustainable cleantech consulting firm Alpin. Mostadam is a standard that includes three stand-alone green building rating systems depending on the type of built asset being examined: residential buildings, communities, and commercial buildings. Each rating system has two elements- the first is design and construction, and the second is operational and existing.

Mostadam is tailored to Saudi Arabia's regional needs, local climate, and environmental characteristics. The benefits of Mostadam will be manifold. This new green building rating system will help to create a more sustainable construction industry in Saudi Arabia, as well as improve the overall quality of construction projects in the region. Other benefits include the rating system's social impact, as it is designed to support Saudi Arabia's economy and job growth. Furthermore, Mostadam is designed to comply with local legislation, 
and it prioritizes local design and focuses on local culture. Generally, the initiatives of such a standard will bring significant energy-saving benefits to sustainable buildings. Social and economic benefits can also be obtained, such as better ventilation, better working and living environments, increased working productivity, and even higher rents, sale prices, and rates of occupancy.

In the present paper, different issues related to the development of sustainable buildings in Saudi Arabia are discussed. These issues may be considered as the motivation for launching the Saudi rating system known as Mostadam. The effects of indoor environmental quality on the rating system are briefly discussed. Moreover, the main categories of the Mostadam rating system are explored in comparison with the international LEED rating system. Finally, some important strategies are suggested in order to promote the development of sustainable buildings in Saudi Arabia according to the principles of Saudi Arabia's vision 2030.

\section{Buildings Design and Privacy of Saudi Society}

Building design in Saudi Arabia is strongly related to its local climate conditions and geography. Saudi Arabia is located in western Asia, with different climate regions ranging from the Mediterranean to the subtropical desert climate. Figure 1 shows the different climate zones in Saudi Arabia [12].

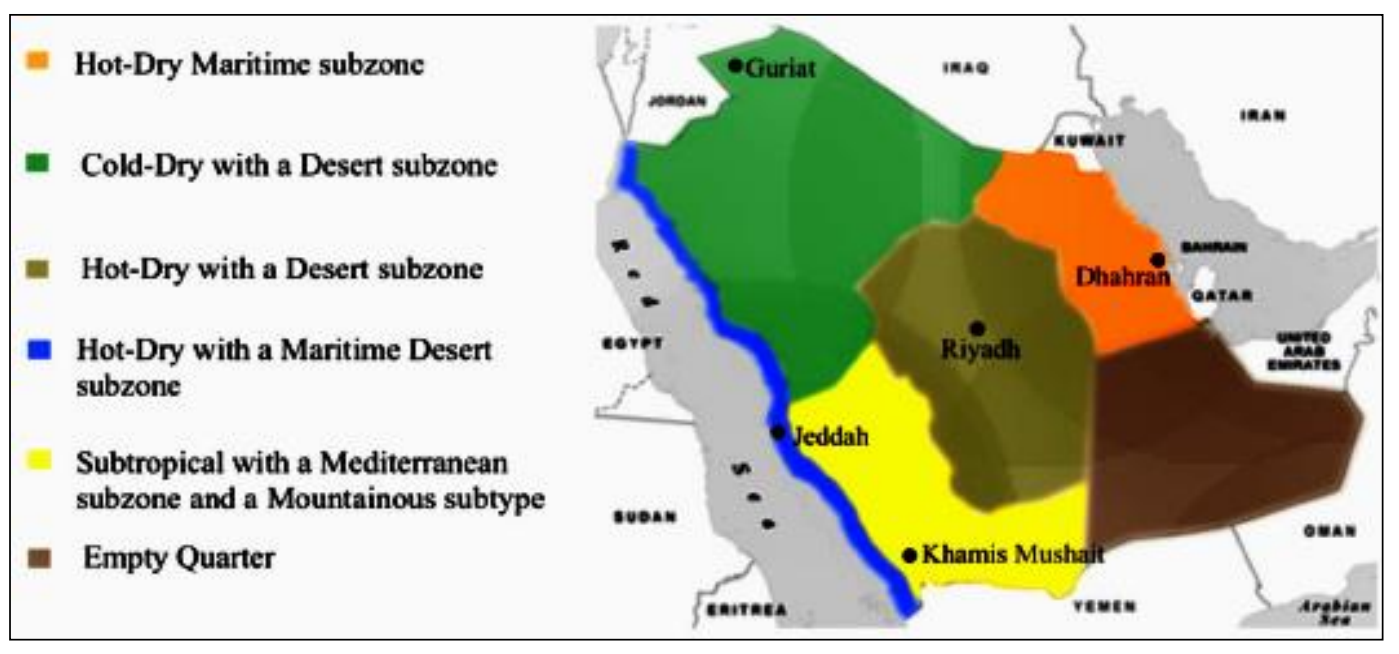

Figure 1. The different climate zones of Saudi Arabia [12].

These different climate conditions in Saudi Arabia lead to different building architecture designs and construction methods. According to the Islamic culture of Saudi Arabia, the users of residential buildings try to reflect their strong adherence to the Islamic religion and their sense of self-identity. Moreover, the users also try to organize the interior spaces of their houses according to their daily needs. Therefore, building designs in Saudi Arabia are normally influenced by the user's social needs or need for privacy.

\section{Sustainable Buildings in Saudi Arabia}

Saudi Arabia has recently pursued building sustainability as a result of its large economic and population growth. The main objectives are to reduce the per capita carbon dioxide emissions and per capita electricity consumption by increasing the number of sustainable buildings to promote the sustainable development of the community. In general, the leading Gulf Cooperation Council (GCC) countries in terms of the total number of projects registered and rated by LEED are Saudi Arabia and the United Arab Emirates [7]. However, the number of certified green buildings in Saudi Arabia is notably low compared with that of other countries in the Gulf Cooperation Council (GCC) [8]. 
Table 1 shows the number of registered projects and the number of certified projects according to the different rating systems and certification levels in Saudi Arabia and the UAE. It can be seen from Table 1 that it is necessary for Saudi Arabia to strive to register and approve many new projects. Moreover, all of the certified buildings in Saudi Arabia are rated by the US Green Building Council LEED rating system and not by a national rating system. The main problem is that international sustainable building rating systems do not take into account regional differences. Therefore, it is important to develop a Saudi local rating system that is tailored to Saudi Arabia's local climate and environmental characteristics. Moreover, most international rating systems include specific technical criteria inspired by the local country-specific standards or regulations, and these criteria cannot feasibly be applied in other countries.

Table 1. The total number of projects registered and certified by Leadership in Energy and Environmental Design (LEED) in Saudi Arabia and the UAE [8].

\begin{tabular}{|c|c|c|c|c|c|c|}
\hline Country & $\begin{array}{c}\text { No. of Registered } \\
\text { Projects }\end{array}$ & Rating System & Rating Version & \multicolumn{3}{|c|}{ Certified Projects } \\
\hline Saudi Arabia & 159 & $\begin{array}{l}\text { LEED BD + C New } \\
\quad \text { Construction }\end{array}$ & $\begin{array}{c}\text { LEED } 2.2 \\
\text { LEED } 2009 \\
\text { LEED v4 }\end{array}$ & 22 & $\begin{array}{l}\text { Platinum } \\
\text { Gold } \\
\text { Silver } \\
\text { Certified }\end{array}$ & $\begin{array}{l}4 \\
9 \\
7 \\
2\end{array}$ \\
\hline $\begin{array}{c}\text { United Arab } \\
\text { Emirates }\end{array}$ & 594 & $\begin{array}{l}\text { LEED BD + C New } \\
\text { Construction }\end{array}$ & $\begin{array}{c}\text { LEED } 2.2 \\
\text { LEED } 2009 \\
\text { LEED v4 }\end{array}$ & 139 & $\begin{array}{l}\text { Platinum } \\
\text { Gold } \\
\text { Silver } \\
\text { Certified }\end{array}$ & $\begin{array}{l}12 \\
76 \\
37 \\
14\end{array}$ \\
\hline
\end{tabular}

The illustrated data in Table 1 refer to the lack of development of the Saudi building industry in terms of the use of modern building materials and techniques, as assessed by different previous investigations [8]. Moreover, work experience and level of education have important effects on sustainable building development in the community. Recently, through a systematic qualitative research approach, barriers to the diffusion and adoption of green buildings in Saudi Arabia have been explored [13]. Around 14 sustainable building barriers have been identified and categorized into different groups, which include financial, governmental, technical, cultural, and market barriers. Some important recommendations have been made in order to assist in overcoming the identified barriers [14].

To overcome all the previous barriers, preserve the real estate market value, and draw investments to the sustainable buildings sector, Saudi Arabia introduced its new building rating system, Mostadam, in October 2019. This new standards initiative was developed by the Ministry of Housing for Saudi Arabia as a guide to a sustainable buildings rating system for new as well as existing buildings in Saudi Arabia.

\section{Categories of Residential Buildings in Saudi Arabia}

Residential buildings in Saudi Arabia can be categorized into three major types: modern building blocks, which contain a number of flats, villas and traditional houses (Figure 2). Modern building blocks are distinguished in Saudi Arabia.

Based on the survey conducted in our recent study on a total of nearly 1500 people [15], more than 55\% of Saudi citizens live in building blocks (Figure 3). In addition to this, about $40 \%$ say that they live in a separate modern house or villa, while less than $5 \%$ live in traditional houses. These traditional houses are considered to be old buildings, were usually built before 1950, and were constructed using traditional locally developed building materials such as clay and stone. This type of local traditional building material has a beneficial characteristic of thermal mass, which aids a building in adapting to the hot climate in Saudi Arabia with the absence of an air conditioning system. There are some recent studies that focus on the durability and resistance of old and historic buildings in Saudi Arabia compared with more modern buildings [15]. 


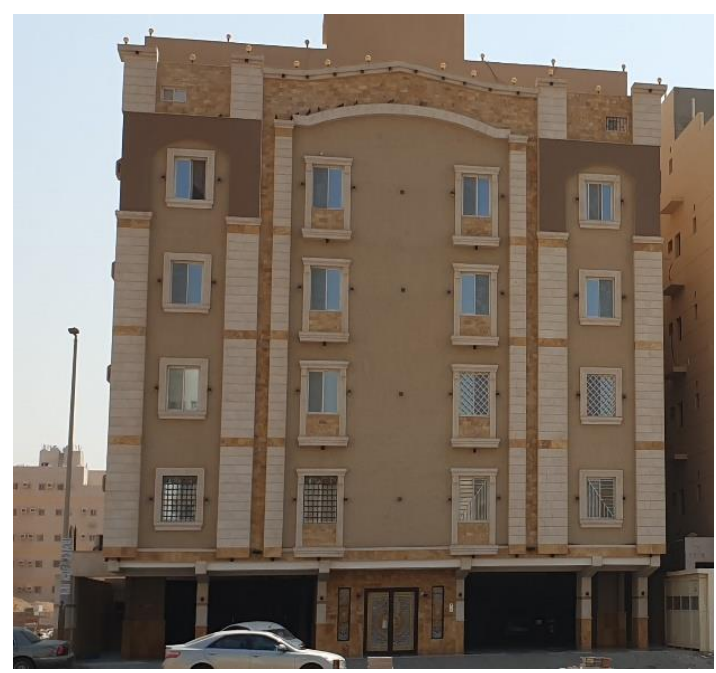

(A)

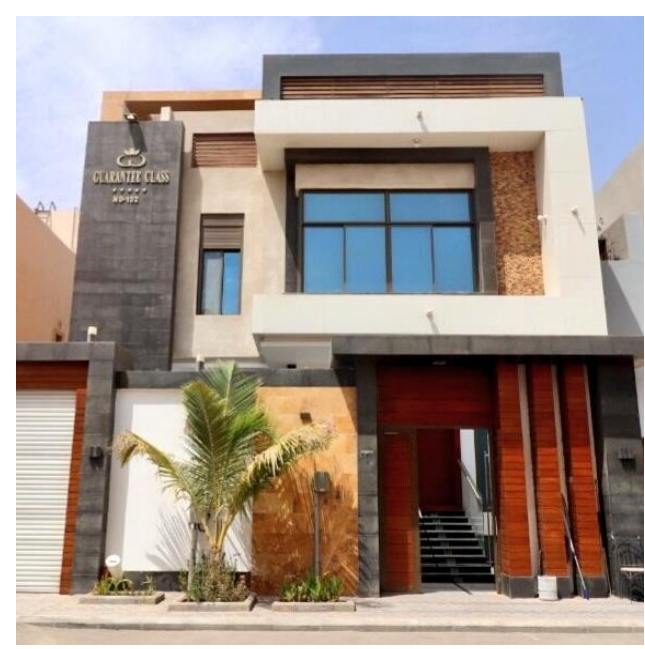

(B)

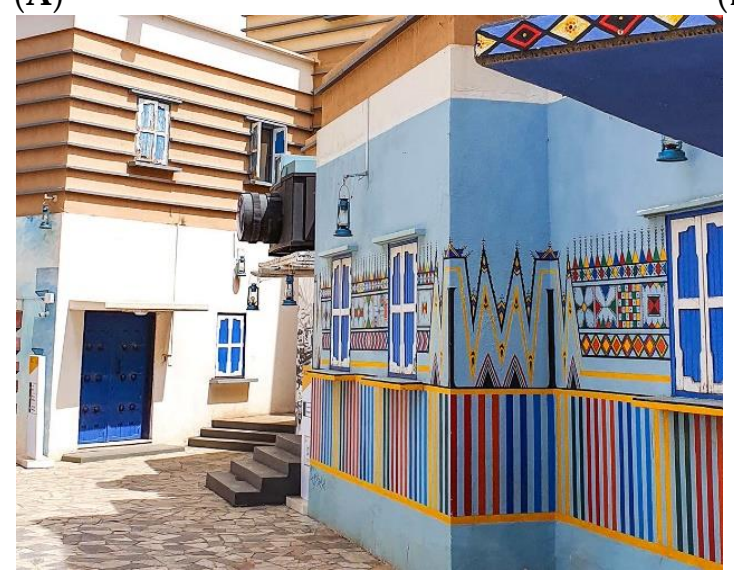

(C)

Figure 2. Categories of residential buildings in Saudi Arabia, where (A) shows a residential building block (flats), (B) shows a villa, and (C) shows a traditional house built with high-thermal performance materials [15].

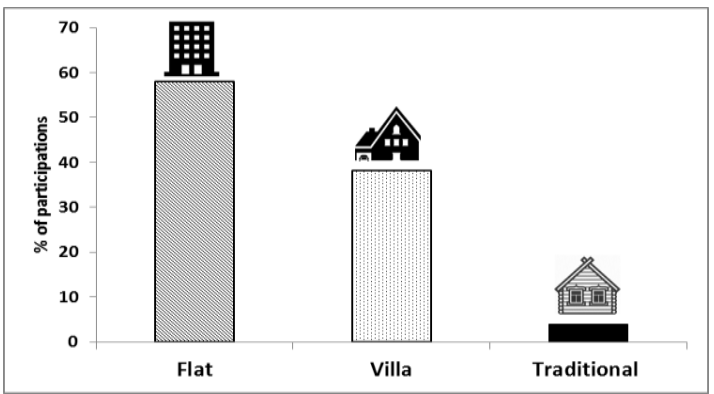

Figure 3. Percentage of residents who participated in the survey.

\section{Indoor Environmental Quality and Thermal Comfort}

Rating systems, whether they are local or international, are linked to indoor environmental quality and thermal comfort. Indoor environmental quality can be broadly affected by eight main factors, including thermal comfort, ventilation, and thermal mass (TM), which is strongly linked to thermal comfort [16].

Thermal mass (TM) can be categorized into two major groups: internal TM, such as furniture, and external TM, such as walls, roofs, and floors [17]. The use of TM can be influential in controlling the energy load and preserving thermal comfort for occupants [18-20]. Thermal mass is more functional in warm climates where the outdoor temperatures rise sharply [21] and also in cold regions that experience hot summers [22,23]. Kumar [24] 
highlighted that the use of thermal mass is not only effective in hot regions but also in composite climates, such as in India. In addition, Rodrigues [25] considered the link between energy consumption and TM in the Mediterranean climate and stated that thermal transmittance alters based on the local climate. A comprehensive comparison between a historical building that was built with stone and a modern one that was built with bricks was conducted by Yousef [26] in Egypt, which has a hot climate. The study determined that the building materials used in historical buildings aid in lowering the indoor air temperature by $1.4{ }^{\circ} \mathrm{C}$. According to a study carried out by Kumar [27], $40 \%$ to $98 \%$ of occupants' discomfort can be avoided when using thermal mass. Due to the importance of indoor environmental quality in sustainable buildings, the adjustment of the corresponding assessment fields in the rating systems should be investigated. Therefore, in the Mostadam rating system, which is considered in the present study, a category called health and comfort has been designed for indoor environmental quality evaluation according to the geographical aspects and local priorities of Saudi Arabia. In this category, different items and parameters related to indoor environmental quality have been evaluated. The key objectives of this category are to assess the quality of the indoor environment in terms of thermal comfort, noise and acoustics, ventilation rate, indoor emitting material, daylight, visual comfort, the health level of residents, and also outdoor thermal comfort.

\section{Research Methodology}

There are two major methods used to evaluate and observe indoor environmental quality in residential buildings in Saudi Arabia. The first method is based on a survey to question people in the country regarding their thermal comfort preference. Registration with a local or international rating system is linked to the actual comfort level in buildings.

In general, rating systems are linked to energy performance in residential buildings as well as thermal comfort. According to the results derived from a survey of about 1500 participants in Saudi Arabia (Figure 4), the survey took place in winter, as it may be possible to achieve thermal comfort in this time due to the lower outdoor air temperatures. It can be noticed that residents of villa buildings experienced a higher percentage of discomfort due to the building style's greater exposure to outdoor conditions, meaning that more heat transfer occurs. On the other hand, residents of flats experience a very large percentage of discomfort from excess warmth even in winter. This is due to limited exposure to outdoor conditions. As a result, the priority of the rating system also depends on the type of building assessed.

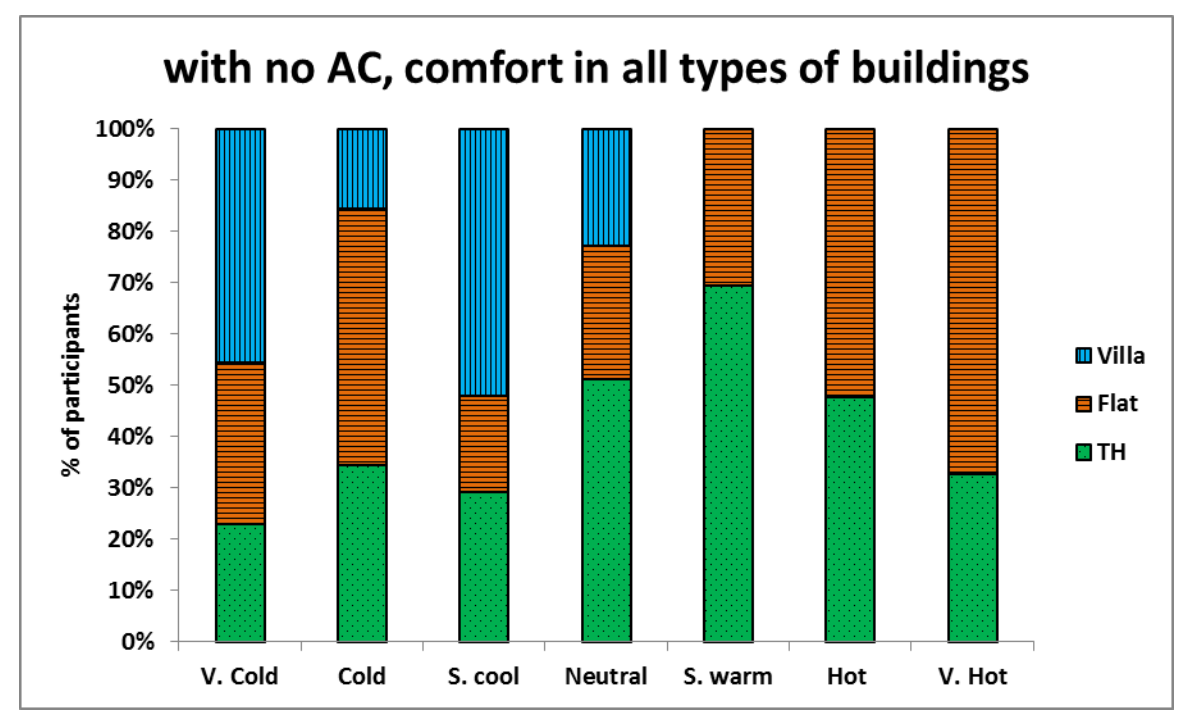

Figure 4. Thermal comfort sensation of occupants living in different types of buildings in a survey on about 5000 participations, where $\mathrm{TH}$ is a traditional house. The survey is based on winter weather conditions. 
The second method is based on the site monitoring of two residential buildings to compare the impact of different building construction materials on indoor environmental quality and thermal comfort. Table 2 shows the difference in characteristics between traditional and modern buildings. The results obtained here are based on the direct measurement of the indoor temperature in ${ }^{\circ} \mathrm{C}$ and the relative humidity $(\mathrm{RH} \%)$.

Table 2. Comparison of building construction between old (traditional) and modern buildings.

\begin{tabular}{|c|c|c|c|c|}
\hline & Material & Thickness (mm) & Conductivity (W/m K) & Total $U$-Value $\left(\mathrm{W} / \mathrm{m}^{2} \mathrm{~K}\right)$ \\
\hline \multicolumn{5}{|c|}{ Traditional case model (palace as it is) } \\
\hline External wall & Stones & 450.00 & 1.31 & 1.4 \\
\hline \multirow{2}{*}{ Roof } & Wood bars & 88.00 & 0.11 & \multirow{2}{*}{0.44} \\
\hline & Mud & 200.00 & 0.87 & \\
\hline Ground & Stones & 450.00 & 1.31 & 1.4 \\
\hline \multicolumn{5}{|c|}{ Modern building construction } \\
\hline External wall & Concrete block & 200.00 & 1.31 & 3.1 \\
\hline \multirow{2}{*}{ Roof } & Thermal insulation & 125 & 0.04 & \multirow{2}{*}{0.22} \\
\hline & Concrete slap & 200 & 1.31 & \\
\hline \multirow{3}{*}{ Ground } & Concrete foundation & 300 & 0.87 & \multirow{3}{*}{0.35} \\
\hline & Crushed aggregate & 75 & 0.55 & \\
\hline & Clay soil & 1000 & 0.70 & \\
\hline
\end{tabular}

Figure 5 shows that traditional buildings that were constructed with heavy thermal mass materials, such as clay and stone, have a more fluctuating indoor temperature as well as relative humidity. This was reflected in the thermal preferences of the residents of such buildings, as most of the occupants stated that they were on the neutral or warmer side, even though it was wintertime. In contrast, people living in villas experienced a high percentage of cold sensations in the operation of a free-running system.
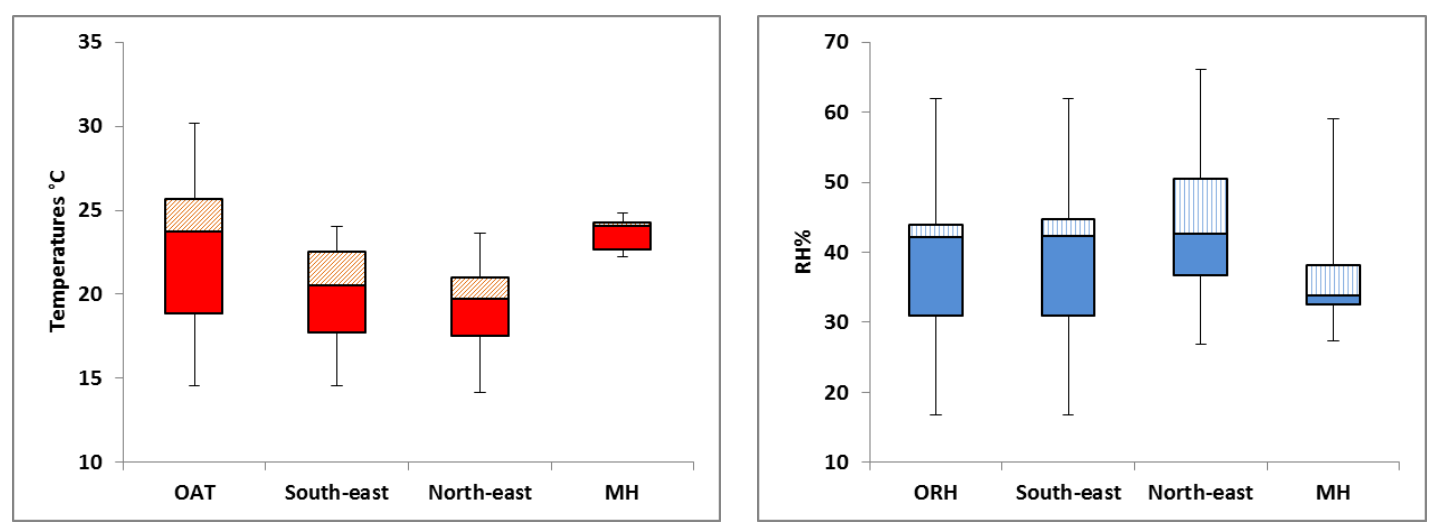

Figure 5. Comparison between modern building design and traditional one built 90 years ago, where $\mathrm{MH}$ is a modern house, and all directions are monitored in a traditional building, where OAT is outdoor air temperature $\left({ }^{\circ} \mathrm{C}\right)$, ORH is outdoor relative humidity $(\%)$ [15].

This indicates that rating systems may be more crucial to modern buildings, which have not received due consideration of their environment and climate aspects compared to old buildings.

\section{Categories of "Mostadam" Rating System versus LEED v4.1}

The Saudi Housing Ministry has recently launched 16 initiatives in order to boost the Kingdom's real estate market in order to support residential infrastructure and increase 
buildings' market value. One of the most important initiatives announced by the Saudi Housing Ministry is the "Mostadam" initiative, as a result of its many benefits and extra goals for the real estate sector [28]. Moreover, "Mostadam" is related to the Saudi Building Code (SBC) and was designed to be consistent with the existing legislature.

The present study applies an alternative methodology based on qualitative analysis to investigate and analyze the impact of building construction on indoor environmental quality (IEQ) and thermal comfort. First of all, the local "Mostadam" rating system was compared with the international system, which is called LEED [29]. This clearly shows the strength of the local rating system, which can be used to enhance the public's confidence in applying for sustainable building accreditation.

The most important benefits of the Mostadam rating system can be summarized as follows:

- To expand and promote sustainable development in the building sector to support the Saudi Vision 2030;

- To improve the building standards in Saudi Arabia for a better future and lifestyle;

- To ensure that new buildings are built according to safety and security standards;

- To boost the quality of buildings and the confidence index;

- To preserve the market value and increase the median age of buildings;

- To attract investments in the estate sector;

- To increase the water and energy efficiency of buildings;

- To ensure a healthy and comfortable indoor environment;

- $\quad$ To reduce the operation and maintenance costs of housing units;

- To reduce potential risks in the housing construction process and the costs entailed by them;

- To increase the practical adaptability of change in the construction industry by integrating sustainability;

- $\quad$ To provide continuous quality inspections for different buildings units;

- To increase competition between service providers and beneficiaries in the real estate market by issuing certificates of different levels for approved buildings;

- To increase public awareness of the sustainability concept and appropriate technologies.

There are three rating systems in Mostadam: Rating system \#1, Rating system \#2, and Rating system \#3, which are directed at residential buildings, commercial buildings, and communities, respectively. Each rating system consists of two elements. The first is Element \#1, for design and construction $(D+C)$, and the second is Element \#2 for operational and existing $(\mathrm{O}+\mathrm{E})$. These can be summarized as follows:

- Mostadam Rating system \#1:

Element \#1.1 Mostadam Rating System for Residential Buildings D + C;

Element \#1.2 Mostadam Rating System for Residential Buildings O + E.

- Mostadam Rating system \#2:

Element \#2.1 Mostadam Rating System for Commercial Buildings D + C; Element \#2.2 Mostadam Rating System for Commercial Buildings O + E.

- Mostadam Rating system \#3:

Element \#3.1 Mostadam Rating System for Communities Buildings D + C;

Element \#3.2 Mostadam Rating System for Communities Buildings O + E.

Recently, the "points and criteria" for Mostadam rating system Element \#1.1 were identified [28]. The other rating systems and relevant elements are still under construction. Consequently, it is worth providing a short comparison between the recent version of LEED, v4.1, which was published in January 2019 as a modified version of LEDD v4, and the points and criteria of the Mostadam rating system Element \#1.1. Table 3 shows a comparison between the categories of LEED v4.1 and the Mostadam rating systems for residential buildings $\mathrm{D}+\mathrm{C}$ and the total points for each category. 
Table 3. Comparison between the categories of LEED v4.1 and the Mostadam rating system Element \#1.1).

\begin{tabular}{ccccc}
\hline Item No. & Category in LEED v4.1 & $\begin{array}{c}\text { Total } \\
\text { Points }\end{array}$ & $\begin{array}{c}\text { Category in Mostadam Rating System_Element \#1.1 } \\
\text { (Res. Buildings D + C) }\end{array}$ & $\begin{array}{c}\text { Total } \\
\text { Points }\end{array}$ \\
\hline 1 & Integrative Process & 1 & Transportation and Connectivity \\
2 & Location and Transportation & 9 & Site Sustainability & 7 \\
3 & Sustainable Sites & 9 & Water & 9 \\
4 & Water Efficiency & 11 & Energy & 24 \\
5 & Energy and Atmosphere & 35 & Materials and Waste & 27 \\
6 & Materials and Resources & 19 & Health and Comfort & 4 \\
7 & Indoor Environmental Quality & 16 & Education and Innovation & 4 \\
8 & Innovation & 6 & Region and Culture & 7 \\
9 & Regional Priority & 4 & Policies, Management\& Maintenance \\
10 & & & \\
\end{tabular}

To illustrate the above data in a graph comparison, Figure 6 shows an illustration for better comparison.

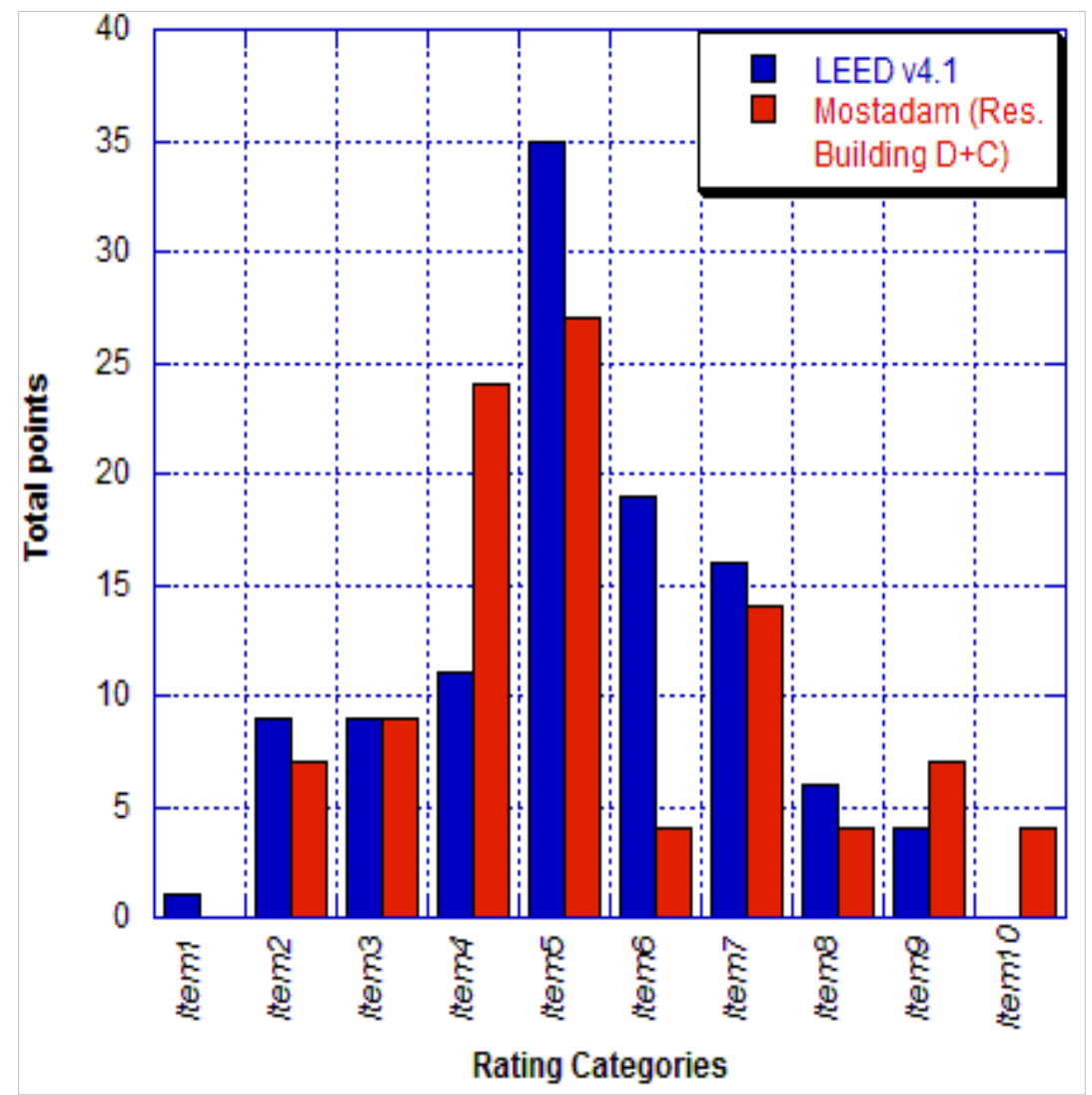

Figure 6. Total point comparison for the categories of LEED v4.1 and the Mostadam rating system Element \#1.1 (res. buildings D + C).

From Table 3 and Figure 6, we can make some important remarks and comments:

- $R_{1}$. The integrative process category in LEED is not included in Mostadam;

- $C_{1}$. The integrative process is an early analysis that starts in the programming and predesign phases; consequently, it has less importance in Mostadam;

- $\quad R_{2}$. The location and transportation category in LEED has been replaced by the transportation and connectivity category in "Mostadam" (9:7 points);

- $C_{2}$. This gives an indication of the strength and quality of the existing road networks in Saudi Arabia; 
- $\quad R_{3}$. The sustainable sites category in LEED has the same effect in Mostadam;

- $C_{3}$. This can be seen as the importance of site sustainability in both rating systems;

- $R_{4}$. The water efficiency category in Mostadam has a more important effect on the evaluation process than that included in LEED (24:11 points);

- $\quad C_{4}$. This is due to the high consumption of water per person in Saudi Arabia (around $270 \mathrm{~L}$ per capita), which is considered to be double the world's average consumption;

- $\quad R_{5}$. The energy category in Mostadam has little effect on the evaluation process compared to that included in LEED (27:35 points);

- $\quad C_{5}$. This concerns the diversity and availability of renewable and traditional energy resources in Saudi Arabia;

- $\quad R_{6}$. The material and waste category in Mostadam has very little effect on the evaluation process compared to that included in LEED (4:19 points);

- $C_{6}$. This is an important point and may be referred to as the lack of a sustainable construction industry and recycling technology for waste material in Saudi Arabia;

- $R_{7}$. Indoor environmental quality in LEED has a similar effect to that in the "Mostadam" rating system; however, it has a different category title: "Health and Comfort" (16:14 points);

- $\quad C_{7}$. This can be attributed to the importance of such a category in both rating systems. Moreover, this category is considered to be the most important category in all sustainable building rating systems. Therefore, this category will be explained in more detail in the following section;

- $R_{8}$. The innovation category in LEED is named "Education and Innovation" in Mostadam; however, a slight difference in the points can be observed (6:4 points);

- $C_{8}$. This can be attributed to the lesser importance of the innovation category in "Mostadam" due to the redundant design of residential buildings in Saudi Arabia;

- $R_{9}$. The regional priority category in LEED is named "Region and Culture" in "Mostadam"; however, the total points are increased (4:7 points);

- $\quad C_{9}$. This refers to the importance of privacy in sustainable building design in Saudi society, as explained previously in Section 2;

- $R_{10}$. The "Policies, Management, and Maintenance" category in Mostadam is not included in LEED;

- $C_{10}$. This is an additional category in Mostadam, and it is considered to be an important category related to people's behavior in the Saudi community. Moreover, it has 4 points, which reveals the importance of the management and maintenance policies adopted in Saudi sustainable residential buildings.

\subsection{Assessment of IEQ in LEED v4.1 and Mostadam Rating Systems}

Indoor environmental quality is considered to be one of the most important categories in any sustainable building rating system. Therefore, many international as well as local rating systems worldwide have turned increased attention to the definition of the IEQ category and the associated credit points. This category exists under different titles-e.g., "health and wellbeing" in BREEAM; indoor environment quality in LEED, CASBEE, and SBTool [4]; and "Health and Comfort" in the Mostadam rating system [28]. Generally, most of the international rating systems, such as LEED and BREEAM, have been used for the assessment of the IEQ of sustainable buildings in different countries regardless of their geographical aspects, local priorities, privacy, and microclimate conditions. Therefore, local rating systems can overcome such problems to achieve a reasonable and believable evaluation and to gather the most dependable evaluation results while surveying structures in countries. In general, the key objectives of any sustainable building rating system are to achieve a high-quality indoor environment for a building's occupants through enhancing their thermal comfort and creating a comfortable, healthy, and productive indoor environment.

To obtain a high-quality indoor environment using the "Mostadam" rating system, which is considered in the present study, the category of "Health and Comfort" has been 
developed, and the included criteria aim to enhance indoor thermal comfort evaluation. Therefore, a comparison between the individual items included in the "Health and Comfort" category in the "Mostadam" rating system and the indoor environmental quality category existing in LEED v4.1 should be made. The selection of LEED rating systems is based on a large number of LEED-certified projects in Saudi Arabia [29]. Table 4 shows the strategy for assessing the indoor environment quality according to the LEED v4.1 and "Mostadam" rating systems.

Table 4. Assessment of IEQ in both the LEED v4.1 and Mostadam rating systems.

\begin{tabular}{|c|c|c|c|c|}
\hline Item No. & $\begin{array}{c}\text { LEED v4.1 } \\
\text { “Indoor Environmental Quality" }\end{array}$ & Credit Points & $\begin{array}{l}\text { Mostadam } \\
\text { "Health and Comfort" }\end{array}$ & Credit Points \\
\hline 1 & $\begin{array}{c}\text { Enhanced Indoor Air } \\
\text { Quality Strategies }\end{array}$ & 2 & Ventilation & 1 \\
\hline 2 & $\begin{array}{l}\text { Construction Indoor Air Quality } \\
\text { Management Plan }\end{array}$ & 1 & Outdoor Space & 1 \\
\hline \multirow{2}{*}{3} & \multirow{2}{*}{ Indoor Air Quality Assessment } & \multirow{2}{*}{2} & Indoor Air Quality & 1 \\
\hline & & & Active Residents & 1 \\
\hline \multirow{2}{*}{4} & \multirow{2}{*}{ Thermal Comfort } & \multirow{2}{*}{1} & Indoor Thermal Comfort & 2 \\
\hline & & & Outdoor Thermal Comfort & 2 \\
\hline 5 & Daylight & 2 & \multirow{2}{*}{ Daylight and Visual Comfort } & \multirow{2}{*}{2} \\
\hline 6 & Interior Lighting & 1 & & \\
\hline 7 & Low-Emitting Materials & 3 & $\begin{array}{l}\text { VOCs and Low-Emitting } \\
\text { Materials }\end{array}$ & 2 \\
\hline 8 & Quality Views & 2 & Access for All & 1 \\
\hline \multirow[t]{2}{*}{9} & Acoustic Performance & 2 & Acoustics & 1 \\
\hline & Total Points & 16 & & 14 \\
\hline
\end{tabular}

From Table 4, we can conclude with some important remarks related to the "Mostadam" rating system:

- $\quad R_{1}$. The "Mostadam" rating system includes an individual item for ventilation.

- $R_{2}$. The "Mostadam" rating system includes, in addition to the indoor thermal comfort, a new individual item for outdoor thermal comfort, which contributes to pedestrians' health and satisfaction with the thermal surroundings.

- $\quad R_{3}$. The total weight of the thermal comfort category in the "Mostadam" rating system (4 to 1 point), compared with its corresponding category in LEED v4.1.

- $\quad R_{4}$. Other items in both the "Mostadam" and LEED v4.1 rating systems may have the same weight and importance.

Obviously, the above comparison showed that the "Mostadam" rating system could improve the indoor thermal comfort evaluation or more and the indoor environmental quality evaluation compared to LEED v4.1.

\subsection{Credit Points for Individual Categories of "Mostadam" Rating System}

It can be noticed that in the Mostadam rating system Element \#1.1, in addition to site sustainability, the most important categories are the energy, water, and health and comfort categories for the certification process of Saudi sustainable buildings. In more detail, the sub-points of each category and their credit points can be seen in Table 5 . 
Table 5. Mostadam Rating System for Residential Buildings D + C.

\begin{tabular}{|c|c|c|c|c|c|}
\hline $\begin{array}{l}\text { Item } \\
\text { No. }\end{array}$ & Category & Credit Title & $\begin{array}{l}\text { Core Keystone } \\
\text { Credit Points }\end{array}$ & $\begin{array}{l}\text { Optional Credit } \\
\text { Points }\end{array}$ & $\begin{array}{l}\text { Total Points Per } \\
\text { Category }\end{array}$ \\
\hline \multirow{5}{*}{1} & \multirow{5}{*}{$\begin{array}{l}\text { Transportation and } \\
\text { Connectivity }\end{array}$} & 1. Electric Vehicle Provisions & & 1 & \multirow{5}{*}{7} \\
\hline & & 2. Access to Public Transportation & & 2 & \\
\hline & & 3. Access to Amenities & & 2 & \\
\hline & & 4. Home Office & & 1 & \\
\hline & & 5. Individual Sustainable Transport & & 1 & \\
\hline \multirow{6}{*}{2} & \multirow{6}{*}{ Site Sustainability } & $\begin{array}{l}\text { 1. Sewage, Flood and Rainwater } \\
\text { Management }\end{array}$ & 1 & 1 & \multirow{6}{*}{9} \\
\hline & & 2. Ecological Assessment and Protection & 2 & & \\
\hline & & 3. Construction Environmental Management & & 1 & \\
\hline & & 4. Ecological Enhancement & & 2 & \\
\hline & & 5. Heat Island Effect & & 1 & \\
\hline & & 6. Light Pollution & & 1 & \\
\hline \multirow{4}{*}{3} & \multirow{4}{*}{ Water } & 1. Indoor Water Performance & 3 & 7 & \multirow{4}{*}{24} \\
\hline & & 2. Outdoor Water Performance & 2 & 8 & \\
\hline & & 3. Alternative Water Solutions & & 3 & \\
\hline & & 4. Water Metering & & 1 & \\
\hline \multirow{7}{*}{4} & \multirow{7}{*}{ Energy } & 1. Energy Performance & 5 & 10 & \multirow{7}{*}{27} \\
\hline & & 2. Systems Commissioning & 1 & & \\
\hline & & 3. Envelope Commissioning & & 1 & \\
\hline & & 4. Energy Metering & & 1 & \\
\hline & & 5. Energy Efficient Appliances & & 1 & \\
\hline & & 6. Renewable Energy & & 7 & \\
\hline & & 7. Ozone Impact & & 1 & \\
\hline \multirow{3}{*}{5} & \multirow{3}{*}{ Materials and Waste } & 1. Construction Waste Management & & 1 & \multirow{3}{*}{4} \\
\hline & & 2. Non-Polluting Insulation Materials & & 1 & \\
\hline & & 3. Recycled Materials & & 2 & \\
\hline \multirow{10}{*}{6} & \multirow{10}{*}{ Health and Comfort } & 1. Outdoor Thermal Comfort & 2 & & \multirow{10}{*}{14} \\
\hline & & 2. Indoor Thermal Comfort & 1 & 1 & \\
\hline & & 3. Ventilation & & 1 & \\
\hline & & 4. VOCs and Low-Emitting Materials & & 2 & \\
\hline & & 5. Access for All & & 1 & \\
\hline & & 6. Daylight and Visual Comfort & & 2 & \\
\hline & & 7. Acoustics & & 1 & \\
\hline & & 8. Indoor Air Quality & & 1 & \\
\hline & & 9. Active Residents & & 1 & \\
\hline & & 10. Outdoor Space & & 1 & \\
\hline \multirow{2}{*}{7} & \multirow{2}{*}{$\begin{array}{l}\text { Education and } \\
\text { Innovation }\end{array}$} & 1. Mostadam Guide & 2 & & \multirow{2}{*}{4} \\
\hline & & 2. Innovation & & 2 & \\
\hline \multirow{4}{*}{8} & \multirow{4}{*}{ Region and Culture } & 1. Thriving Economy & & 2 & \multirow{4}{*}{7} \\
\hline & & 2. Heritage and Culture & & 2 & \\
\hline & & 3. Vibrant Society & & 1 & \\
\hline & & 4. Regional Focus & & 2 & \\
\hline & & 1. Residential Waste Management & 1 & & \\
\hline 9 & Policies, Management & 2. Sustainable Procurement & & 1 & 4 \\
\hline & & 3. Building Performance Monitoring & & 2 & \\
\hline
\end{tabular}


More details about the credit titles mentioned in Table 5 can be found in [28]. It can be noticed that the Mostadam rating system can be considered as a modified version of the LEED rating system; however, it contains the privacy and principles of Saudi society and the relevant issues of Saudi vision 2030. Additionally, as described by LEED that there are certification levels according to the total points earned by the project, and there are also corresponding certification levels awarded by Mostadam according to the total points gained for a specified Saudi project. Table 6 shows the certification levels for both the LEED v4.1 and Mostadam rating systems.

Table 6. Certification levels awarded from the LEED v4.1 and Mostadam rating system.

\begin{tabular}{ccccc}
\hline No. & $\begin{array}{c}\text { Certification Levels Awarded } \\
\text { by LEED v4.1 }\end{array}$ & Total Points & $\begin{array}{c}\text { Certification Levels Awarded } \\
\text { by Mostadam }\end{array}$ & Total Points \\
\hline 1 & Certified & $40-49$ points & Green & $20-34$ points \\
2 & Silver & $50-59$ points & Bronze & $35-49$ points \\
3 & Gold & $60-79$ points & Silver & $50-64$ points \\
4 & Platinum & $80-110$ points & Gold & $65-79$ points \\
5 & & & Diamond & $80-100$ points \\
\hline
\end{tabular}

From Table 6, it can be seen that there are differences between the LEED v4.1 and Mostadam certification systems according to the number of certification levels and their earned total points. The certification level provided by Mostadam is considered to be preferred, as it is a new rating system for sustainable buildings in Saudi Arabia. The low total points given for the green certificate, compared with the certified level in LEED, will encourage many new buildings in Saudi Arabia to apply to be sustainable. With further progress, such buildings may gain a better level of certification by considering more categories and items, as described in Table 3.

\section{Guide to Achieving Mostadam Certification}

Any new construction project can gain points according to how well this project complies with the requirements of the Mostadam categories and standards. In the following, the basic steps required for any new project interested in pursuing Mostadam certification will be summarized.

- Decision: The decision to obtain Mostadam certification should stem from all partners involved in the project-e.g., stakeholders, owners, engineers, architects, contractors, occupants, and even the financing banks at the beginning of the process-which will greatly enhance the chance of success;

- $\quad$ Target: The project partners should identify their target certification level according to the initial design of the project; The total budget of the project should be estimated in addition to the certification process charge;

- Registration: The first practical step in the certification process is the registration of the project with the Mostadam registration system on its online website [16]; The registration process will give the project team access to different resources in order to prepare the required project's paperwork;

- Submission: This step should start after completing the required documentation fully and accurately in order to ensure the smooth progress of the certification process;

- Construction: This step is related to the nine Mostadam categories and how the Mostadam rating system awards the points; Each of these categories has baseline prerequisites that must be met to qualify for Mostadam but will not warrant any points unless one goes above and beyond that requirement. The project manager can consult the Mostadam team for any required technical advice.

The Mostadam team will assess a project's performance against the objectives defined previously in the application process and award certification when those objectives have been achieved. 


\section{What Are the Benefits of Mostadam Certification?}

The Mostadam certification program assesses new building designs and construction in terms of some important categories, such as sustainable site, energy efficiency, water usage, material selection, and other environmental factors.

The Mostadam certification program is currently the leading national program for sustainable building design and construction in Saudi Arabia. Obtaining a Mostadam certification demonstrates environmentally responsible building practices. This can be a big boost for all partners involved in the project, such as owners, contractors, designers, and constructors. Moreover, a record of Mostadam-certified projects can help a builder become recognized as a leader in the construction industry. In general, Mostadam-certified buildings can have significant tangible incentives, such as:

- A more sustainable construction industry in Saudi Arabia;

- Improving the overall quality of construction projects in Saudi Arabia;

- Energy saving in sustainable residential buildings;

- Higher indoor environmental quality;

- Increased human productivity;

- User thermal and psychological comfort;

- Increased lease rates;

- Faster sales and higher prices;

- Qualification for a host of incentives, such as zoning allowances and tax rebates;

- Retaining higher property values;

- Attracting more commercial construction companies to the field.

In addition to these advantages, there are some countries that endorse a set of incentive packages for investment in the field of sustainable buildings, which helps specialized companies, individuals, and institutions to start adopting sustainable building practices or start the process of converting existing buildings with the Mostadam rating system.

\section{Conclusions}

Based on Saudi Arabia's vision 2030 for achieving sustainability in all aspects of life, especially in the residential buildings and sustainable cities sector, the "Mostadam" rating system for the evaluation of existing as well as new residential buildings was recently launched. This can be considered as a result of the notably low number of certified green buildings in Saudi Arabia compared with other Gulf countries. The current paper used a survey to conduct a broad examination of the present status of supportable structures in Saudi urban communities. The fundamental classifications of practical private structures, as indicated by the "Mostadam" rating framework, were examined, and the capability of such classifications in Saudi Arabia was investigated. Finally, some recommendations for useful, applicable systems and future arrangements have been made to accomplish a complete change to supportable structures and, therefore, to economical urban areas. That will have the best effect on far-reaching feasible advancement in Saudi Arabia to accomplish vision 2030.

However, there are some critical aspects and challenges which have resulted in a low number of registered projects and buildings in Saudi Arabia-for instance, international sustainable building rating systems do not take into account regional differences and microclimates. As a result, it is essential to develop local rating systems such as Mostadam. In addition to this, it is crucial to explore the lack of development of the Saudi building industry by considering modern building materials and techniques; hence, it is recommended to highly improve the local building industry to overcome this issue and enhance the implementation of the Mostadam rating system throughout the country.

In general, the comparison between the "Mostadam" rating system and LEED v4.1 has shown that it provides an enhancement of indoor thermal comfort evaluation and indoor environmental quality assessment. 
Author Contributions: A.B.: Investigation, Original draft, Conceptualization, Methodology. M.A.: Data Curation, Investigation, Formal analysis, Review \& Editing. All authors have read and agreed to the published version of the manuscript.

Funding: This study was funded by Taif University, Researchers Support Project Number (TURSP2020/196) Taif University, Taif, Saudi Arabia.

Acknowledgments: Authors would like to thank Taif University, Researchers Support Project Number (TURSP-2020/196) Taif University, Taif, Saudi Arabia.

Conflicts of Interest: The authors declare no conflict of interest.

\section{References}

1. Boyle, C.A. Sustainable buildings. In Proceedings of the Institution of Civil Engineers-Engineering Sustainability; Thomas Telford Ltd.: London, UK, 2005; pp. 41-48. [CrossRef]

2. Akadiri, P.O.; Chinyio, E.A.; Olomolaiye, P.O. Design of A Sustainable Building: A Conceptual Framework for Implementing Sustainability in the Building Sector. Buildings 2012, 2, 126-152. [CrossRef]

3. Taleb, H.M.; Sharples, S. Developing sustainable residential buildings in Saudi Arabia: A case study. Appl. Energy 2011, 88, 383-391. [CrossRef]

4. Alyami, S.H.; Rezgui, Y.; Kwan, A. Developing sustainable building assessment scheme for Saudi Arabia: Delphi consultation approach. Renew. Sustain. Energy Rev. 2013, 27, 43-54. [CrossRef]

5. Shaawat, M.E.; Jamil, R. A guide to environmental building rating system for construction of new buildings in Saudi Arabia. Emir. J. Eng. Res. 2014, 19, 47-56.

6. Marzouk, M.; Metawie, M.; Hisham, M.; Al-Sulahi, I.; Kamal, M.; Al-Gahtani, K. Modeling sustainable building materials in Saudi Arabia. In Proceedings of the International Conference on Computing in Civil and Building Engineering 2014, Orlando, FL, USA, 23-25 June 2014; pp. 1546-1553.

7. Asif, M. Growth and sustainability trends in the buildings sector in the GCC region with particular reference to the KSA and UAE. Renew. Sustain. Energy Rev. 2016, 55, 1267-1273. [CrossRef]

8. Alrashed, F.; Asif, M. Saudi Building Industry's Views on Sustainability in Buildings: Questionnaire Survey. Energy Procedia 2014, 62, 382-390. [CrossRef]

9. Abubakar, I.R.; Dano, U.L. Sustainable urban planning strategies for mitigating climate change in Saudi Arabia. Environ. Dev. Sustain. 2019, 22, 5129-5152. [CrossRef]

10. Alardhi, A.; Alaboodi, A.S.; Almasri, R. Impact of the new Saudi energy conservation code on Saudi Arabia residential buildings. Aust. J. Mech. Eng. 2020, 1-15. [CrossRef]

11. Aboneama, W.A. Creating a Unique Sustainable Rating System for Saudi Arabia to Achieve Environmental Assessment and 2030 Vision. Eur. J. Sustain. Dev. 2018, 7, 269. [CrossRef]

12. Alrashed, F.; Asif, M. Climatic Classifications of Saudi Arabia for Building Energy Modelling. Energy Procedia 2015, 75, 1425-1430. [CrossRef]

13. Mosly, I. Barriers to the Diffusion and Adoption of Green Buildings in Saudi Arabia. J. Manag. Sustain. 2015, 5, 104. [CrossRef]

14. Yang, X.; Zhang, J.; Zhao, X. Factors Affecting Green Residential Building Development: Social Network Analysis. Sustainability 2018, 10, 1389. [CrossRef]

15. Alwetaishi, M.; Balabel, A.; Abdelhafiz, A.; Issa, U.; Sharaky, I.; Shamseldin, A.; Al-Surf, M.; Al-Harthi, M.; Gadi, M. User thermal comfort in historic buildings: Evaluation of the potential of thermal mass, orientation, evaporative cooling and ventilation. Sustainability 2020, 12, 9672. [CrossRef]

16. Mujan, I.; Anđelković, A.S.; Munćan, V.; Kljajić, M.; Ružić, D. Influence of indoor environmental quality on human health and productivity-A review. J. Clean. Prod. 2019, 217, 646-657. [CrossRef]

17. Li, Y.; Yam, J.C.W. Designing Thermal Mass in Naturally Ventilated Buildings. Int. J. Vent. 2004, 2, 313-324. [CrossRef]

18. Wolisz, H.; Kull, T.M.; Müller, D.; Kurnitski, J. Self-learning model predictive control for dynamic activation of structural thermal mass in residential buildings. Energy Build. 2020, 207, 109542. [CrossRef]

19. Shan, K.; Wang, J.; Hu, M.; Gao, D.C. A model-based control strategy to recover cooling energy from thermal mass in commercial buildings. Energy 2019, 172, 958-967. [CrossRef]

20. Csáky, I.; Kalmár, F. Investigation of the relationship between the allowable transparent area, thermal mass and air change rate in buildings. J. Build. Eng. 2017, 12, 1-7. [CrossRef]

21. Shaafigh, P.; Asadi, I.; Mahyuddin, N.B. Concrete as a thermal mass material for building applications-A review. J. Build. Eng. 2018, 19, 14-25. [CrossRef]

22. Reilly, A.; Kinnane, O. The impact of thermal mass on building energy consumption. Appl. Energy 2017, 198, 108-121. [CrossRef]

23. Albayyaa, H.; Hagare, D.; Saha, S. Energy \& Buildings Energy conservation in residential buildings by incorporating Passive Solar and Energy Efficiency Design Strategies and higher thermal mass. Energy Build. 2019, 182, 205-213. [CrossRef]

24. Kumar, S.; Tewari, P.; Mathur, S.; Mathur, J. Development of mathematical correlations for indoor temperature from field observations of the performance of high thermal mass buildings in India. Build. Environ. 2017, 122, 324-342. [CrossRef] 
25. Rodrigues, E.; Fernandes, M.S.; Gaspar, A.R.; Gomes, Á.; Costa, J.J. Thermal transmittance effect on energy consumption of Mediterranean buildings with different thermal mass. Appl. Energy 2019, 252, 113437. [CrossRef]

26. Yousef, W.A.; Lang, W. Simulations and quantitative data analytic interpretations of indoor-outdoor temperatures in a high thermal mass structure. J. Build. Eng. 2017, 12, 68-76. [CrossRef]

27. Kumar, S.; Singh, M.K.; Mathur, A.; Mathur, S.; Mathur, J. Thermal performance and comfort potential estimation in low-rise high thermal mass naturally ventilated office buildings in India: An experimental study. J. Build. Eng. 2018, 20, 569-584. [CrossRef]

28. Sustainable Building. Available online: http:/ / www.mostadam.sa (accessed on 22 July 2020).

29. US Green Building Council. Available online: http:/ / www.usgbc.org/projects (accessed on 22 July 2020). 